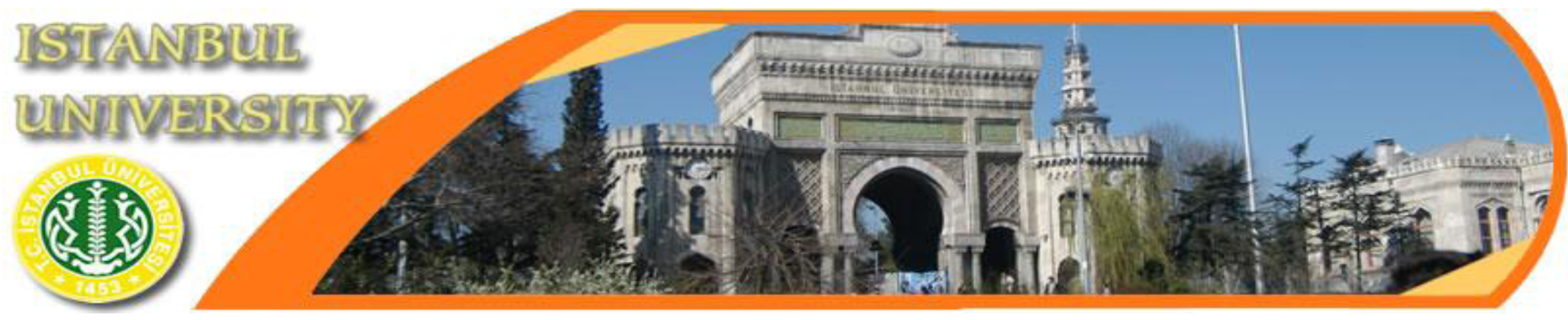

\title{
MANAGEMENT OF URGENT SURGICAL INTERVENTION DUE TO COEXISTENCE OF PHEOCHROMOCYTOMA AND HYDROCEPHALUS IN A PATIENT PRESENTING WITH VON HIPPEL LINDAU SYNDROME
}

\author{
Gulsah Y. Yalin ${ }^{1}$, Ayse K. Uzum ${ }^{1}$, Seher Tanrikulu ${ }^{1}$, Gulcin Yegen ${ }^{2}$, Mehmet Babur ${ }^{3}$, Nurdan Gul ${ }^{1}$, Ferihan Aral ${ }^{1}$, Refik Tanakol ${ }^{1}$ \\ Istanbul University, Istanbul Medical Faculty, Department of Internal Diseases, \\ ${ }^{1}$ Div.of Endocrinology and Metabolism, ${ }^{2}$ Div. of Pathology, Div. of Radiology
}

Von Hippel-Lindau (VHL) disease is a hereditary syndrome with an otosomal dominant pattern and a prevalance of $1 / 36000$. The components of this syndrome are characterised with a variety of benign and malignant tumors such as Hemangioblastomas of the brain (cerebellum) and spine, Retinal angiomas, Clear cell renal cell carcinomas, Pheochromocytomas, Endolymphatic sac tumors of the middle ear, Serous cystadenomas and neuroendocrine tumors of the pancreas, Papillary cystadenomas of the epididymis and broad ligament. The diagnosis is based on the findings of more than one VHL-associated tumor or detection of a germline mutation, particularly in patients with a single manifestation of the condition. Therapeutic efforts are recommended to be focused on avoiding treatment-related morbidity by minimizing the frequency of surgical interventions because of the frequent development of multiple lesions.

We hereby present a case with Von Hippel Lindau syndrome presented with pheochromocytoma, serebellar hemanjioblastoma with hydrocephalus of the third ventricle, and multiple visceral cysts in the pancreas, kidneys and ovaries who had to be operated for in the same surgical session for pheochromocytoma and serebellar hemanjioblastoma.

\section{Case:}

A 41-year-old woman was admitted to our department with headache and hypertension. She described worsening of headaches in the last two months.

On physical examination blood pressure was $150 / 90 \mathrm{mmHg}$, and grade 1 hypertensive retinopathy was present.

Family History: Her sister died at the age of 24 due to pancreas neuroendocrine tumor . Her mother was followed up with multiple pancreatic cysts.

Abdomen MRI revealed a $6 \mathrm{~cm}$ pheochromocytoma lesion on the right surrenal region and multiple cysts in the pancreas, kidneys and ovaries (Figure 1 ).

Urinary catecholamin levels were elevated by six folds. Other laboratory results were normal.

Doxazosin $4 \mathrm{mg}$ (b.i.d) and Amlodipin $5 \mathrm{mg}$ were initiated.

Patient's family history, presence of multiple visceral cysts and pheochromocytoma led us to consider Von Hippel Lyndau sydrome.

Cranium MRI which was performed due to severe headaches revealed a $5 \mathrm{~cm}$ serebellar hemanjioblastoma and hydrocephalus of the third ventricle (Figure 2). Urgent surgical intervention was indicated due to presence of hydrocephalus and risk of herniation. Coexistence of pheochromocytoma, risk of hypertensive crisis and deterioration of herniation with anestesia induction made it mandatory to perform the two surgeries sequentially in the same surgical session.As the patient had been receiving alpha blockers for a sufficient time of preoperative period, laparoscopic right surrenalectomy was performed, followed by hemangioblastoma excision in the same session. Pathological evaluation revealed, right surrenal pheochromocytoma with a Ki score of 3\% (Figure 3) and grade 1 serebellar hemanjioblastoma. Two months after the surgery patient was normotensive without any antihypertensive treatment and symptoms of headache were omitted. Screening of the family members revealed multiple pancreas, renal and epididymal cysts, serebellar hemangioblastoma and pheochromocytoma in her brother compatible with Von Hippel Lindau syndrome and treatment was initiated. Evaluation of the other family members were normal and a surveillance programme was scheduled.

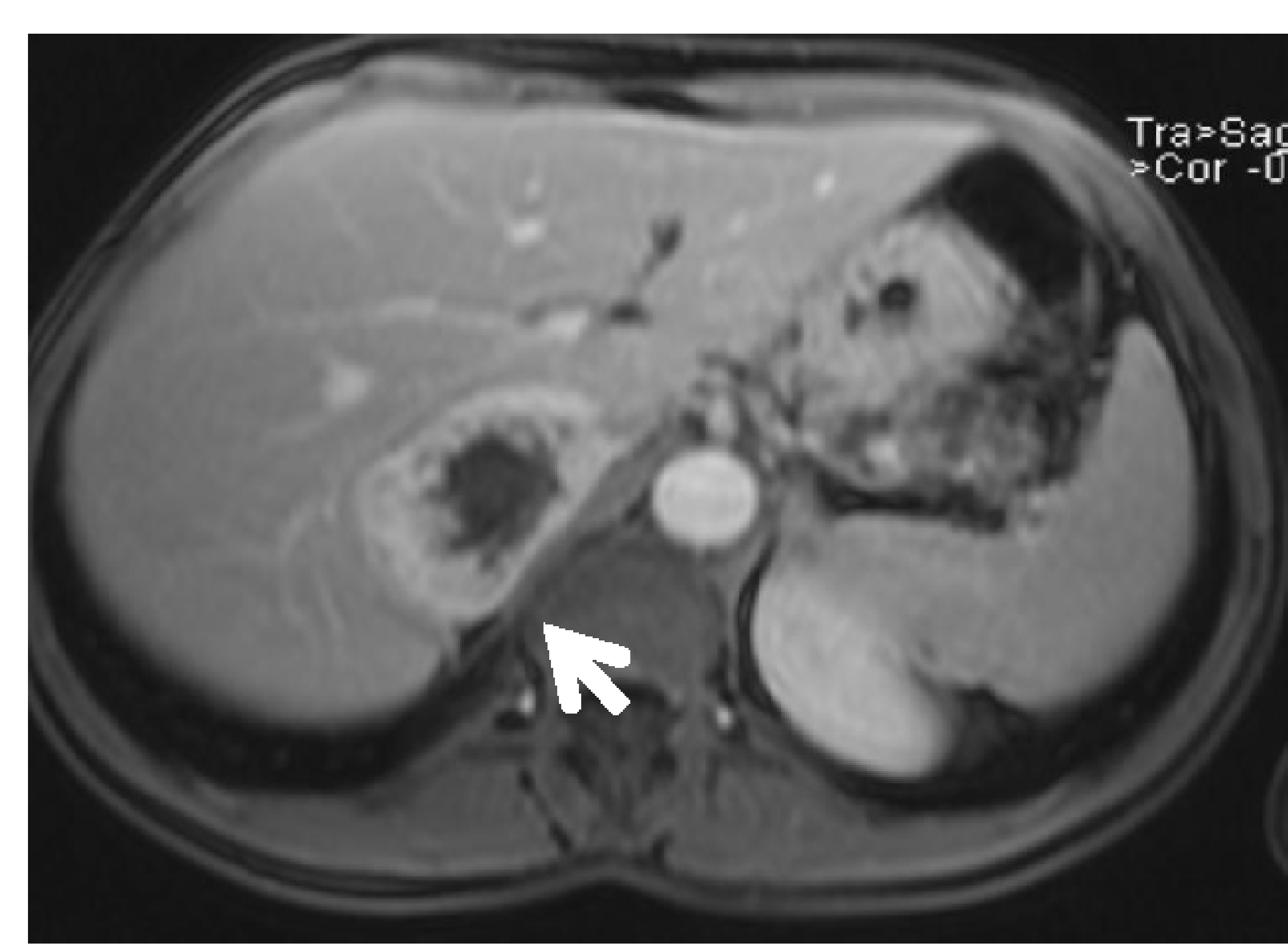

Figure $1.6 \mathrm{~cm}$ right surrenal pheochromocytoma
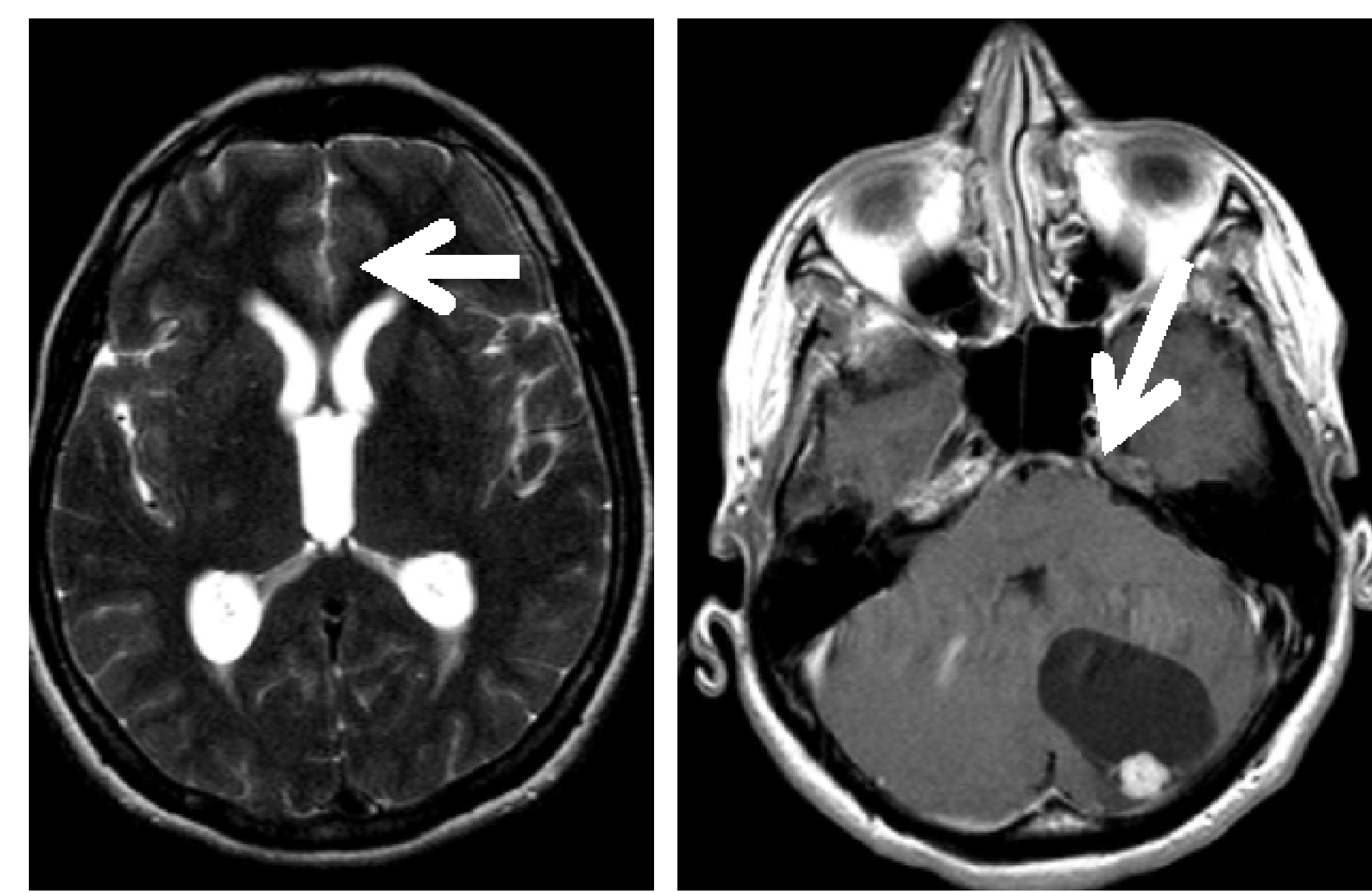

Figure $2.5 \mathrm{~cm}$ serebellar hemanjioblastoma and hydrocephalus of the third ventricle (
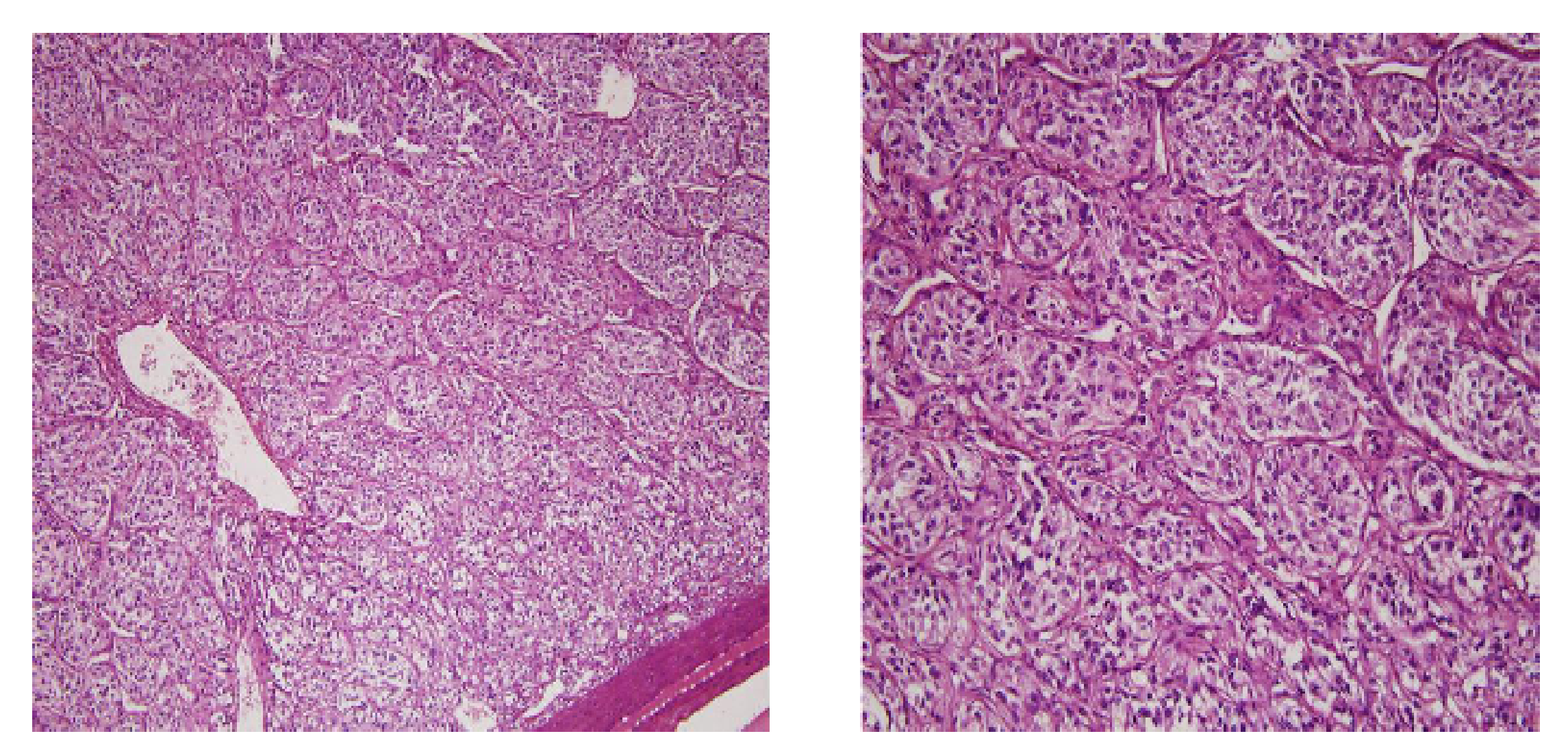

Figure 3. Right surrenal pheochromocytoma

Conclusion: Hemangioblastoma of central nervous system which may complicate the surgery of pheochromocytoma must be considered in patients who present with pheochromocytoma and multisystemic manifestations implicating presence of a genetic syndrome. 